\title{
The Significance of Powder Breakdown During Conveying within Industrial Milk Powder Plants
}

\author{
Irina Boiarkina ${ }^{1}$, Courtney Sang, Nick Depree, Arrian Prince-Pike, Wei Yu, David I. \\ Wilson, Brent R. Young ${ }^{2}$
}

\begin{abstract}
Instant whole milk powder is designed to rapidly dissolve in water, which depends on the particle size distribution (PSD). The fragile powder exiting the dryer is conveyed for packing which breaks down the particles, worsening the dissolution properties. This work investigated the effect of conveying on the final functional properties using two industrial plants with differing transport systems; a pneumatic system and bucket elevator. It was expected that the plant with the bucket elevator consistently produced powder with superior dissolution due to lower breakdown during transport. This was evaluated using the change in PSD. It was found that the plant with the bucket elevator had at least as large a change in the median particle size as the plant with the pneumatic transport system, contrary to the expectation. However, the plant with the bucket elevator had an initially larger particle size, and so the percentage of fine particles that negatively impact dissolution, remained low post transport. When quantified using the change in bulk density, having an initially low bulk density compensated for large increases in bulk density during conveying and powder with lower bulk density pre-transport showed better wettability post transport. Thus in order to produce powder with the desired functionalities the focus should be on improving the initial agglomeration and generating larger particles and lower bulk density pre-transport, as opposed to optimizing the powder transport.
\end{abstract}

Keywords: milk powder, conveying, attrition, particle size

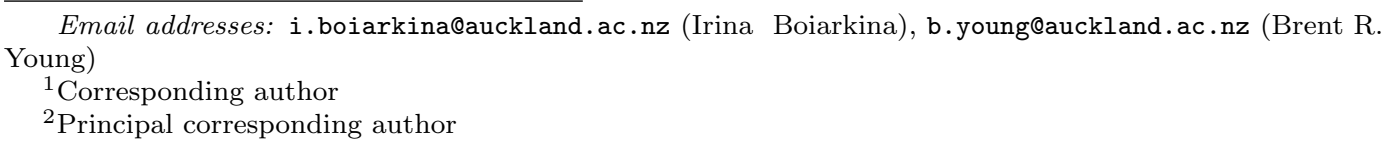




\section{Introduction}

Instant whole milk powder (IWMP) is designed to rapidly reconstitute in water, by improving its dispersibility and wettability functional properties. To achieve this two additional processing steps are carried out over regular whole milk and skim milk powder production: agglomeration and lecithination. Whole milk powder contains a considerable fat fraction, $\approx 26 \mathrm{wt} \%$, which is hydrophobic and thus resists dispersion in water. Therefore, small quantities of an emulsifier, lecithin, are added to improve the wettability of the powder. In addition agglomeration is needed as it involves the combination of multiple milk powder particles into clusters, in order to make the powder more easily dissolvable, and thus impart 'instant' dissolution properties [9, 11]. Good instant dissolution properties are associated with the agglomerate size distribution criteria shown in Figure 1, adapted from [9].

Powder produced at industrial scale requires in-plant transportation before being packed. Because milk powder agglomerates vary in strength they can easily be broken during transportation, resulting in a worsening of the desired instant dissolution properties. The amount of attrition varies depending on the conveying method used [9, 2].

Two industrial IWMP plants were found to consistently produce milk powder with different wettability and dispersibility results. Plant A was found to consistently produce powder that both dispersed and wet faster than Plant B, making it superior in terms of these instant functional properties, as shown in Figure 2. The data shown in Figure 2 were gathered as part of routine measurements at the plants and the analytical methods were similar the ISO 8967|IDF 134:2005 and ISO 17758|IDF 087:2014 standards. These quality parameters were expected to be linked through the particle size distribution of the powder, and it was anticipated that Plant A would have a larger average particle size, due to the superior functional properties. Understanding the

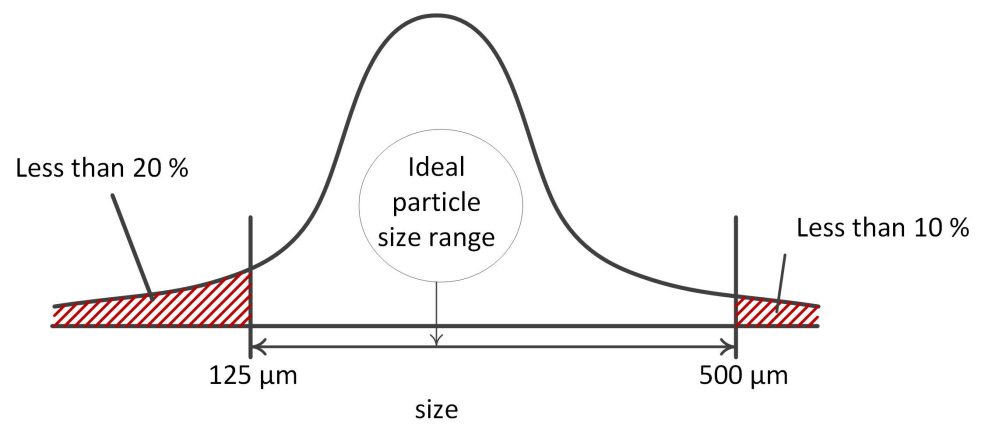

Figure 1: Schematic of the ideal particle size distribution for good instant properties based on the generally agreed suggestions from [9]. 

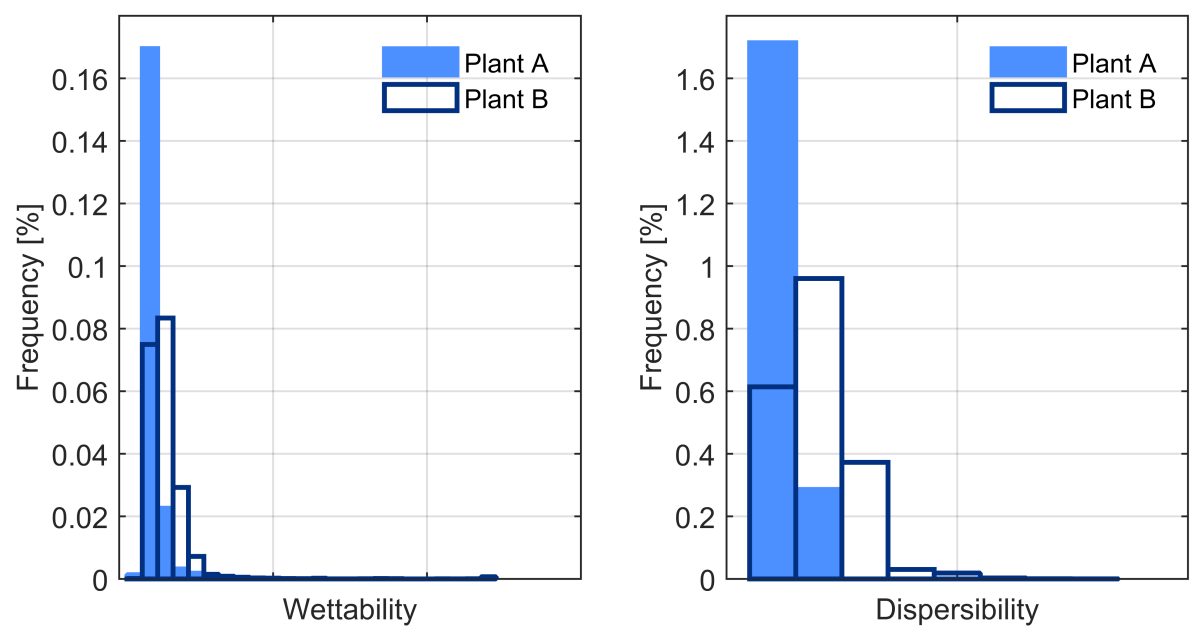

Figure 2: Comparison of the bulk density, wettability and dispersibility of the powder produced at the two different plants. X-scales have been dropped for confidentiality reasons.

contribution of different processing steps to the final product properties is important for working towards real-time quality, which shifts the focus from post-manufacture testing to predicting and controlling the product quality in real-time $[8,6]$.

Although the two plants were of different design, at the plants the difference in the final particle size and instant functional properties had been attributed largely to the differences in the conveying systems, and thus required verification. The two plants have significantly different transport systems, with Plant A being dominated by bucket elevator transport and Plant B being of pneumatic design. Historically, the bucket elevator was considered the more "gentle" transport system, as pneumatic systems have particles accelerated into pipe bends causing significant attrition. Therefore there has been much research into the impact of the design of pipe geometry, transport pressure, solids/airflow mass ratio and transport velocity $[7,5,1,12,4]$. However, much of this has been focused on laboratory scale experimentation and validation of models with these data, whereas the systems encountered in industry are significantly larger.

Pneumatic conveying systems do allow for some optimisation in terms of the sequence of firing of air injectors and air pressures used. However, the overall importance of powder attrition on the final powder properties in an industrial plant has not been studied. Hanely et al. studied the effect of pneumatic conveying parameters on infant formula, however this was again done at the laboratory scale [5]. Therefore it is not clear whether optimisation of the transport parameters at an industrial plant would result in a significant improvement in the milk powder functionality. 
The bucket elevator is the transport system used by Plant A with superior functionality powder. The operators suspected that the superior functionality was due to reduced particle attrition in the bucket elevator. Thus the first hypothesis is that the particle breakdown at Plant A is significantly less than at Plant B. The second hypothesis to be tested is that the state of the powder before transport is more important. The hypotheses were tested by measuring the change in particle size and is discussed in Sections 3.2 and 3.3. As the dataset was limited, this was further tested using historical bulk density data, which was available for multiple seasons of production. The change in bulk density during transport was used as a proxy for the change in particle size. This data was gathered and analysed to establish whether powder produced during periods with reduced breakdown showed superior functional properties within the same plant. This study can be found in Section 3.4.

\section{Methods and Materials}

\subsection{Sampling Locations}

Figure 3 shows the locations of the sampling points used for comparing the breakdown of the powder during transport at the two plants. The two main sample points were located at the end of the fluidised beds, thus pre-transport, and at the exit of the powder storage bins. The powder that exits the storage bins is the powder essentially seen by the customer.

\subsection{Particle Size Characterisation}

Two methods were used for characterising the particle size distribution, laser diffraction and sieving. Although laser diffraction gives high resolution data, it was anticipated that some breakdown of the powder may have been taking place before measurement due to the aggressive air dispersion system. Hence, sieving was used to verify the results.

\subsubsection{Laser Diffraction}

The Malvern Mastersizer 2000 is a laser diffraction instrument used to measure the dry particle size distribution of IWMP. Approximately $30 \mathrm{~g}$ of milk powder was fed into the feed hopper for the dry dispersion system. The metal ball bearings in the inlet sump were removed, as they caused attrition of the sample. The feed pressure adjusted to 0.1 bar and a background reading was taken for $10 \mathrm{~s}$ before the powder feed flow rate was adjusted to the required laser obscuration 


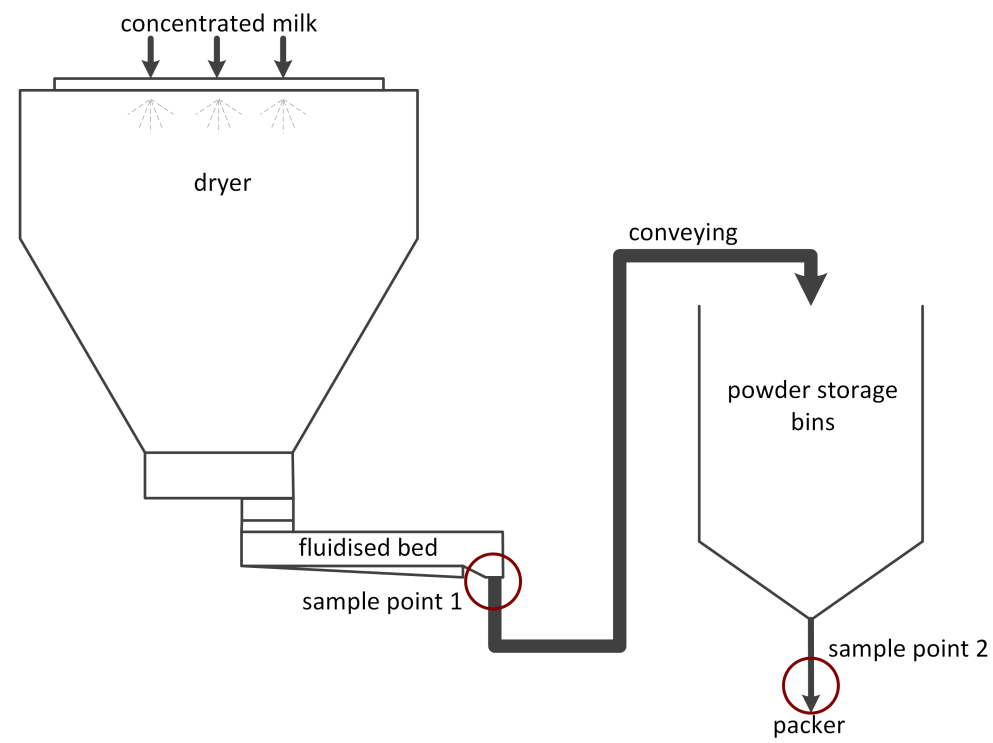

Figure 3: Schematic of the sampling points at the two IWMP plants.

of $1-5 \%$. The sample measurement time was set to $20 \mathrm{~s}$, with a refractive index of 1.46 , and no absorption.

\subsubsection{Sieving}

Sieving was also used to measure the particle size of the powder, however with a much lower particle size bin resolution. This was done as particle size measurement is dependent on the exact way that it is measured [3]. The number of sieves used was restricted to two, to minimize agglomerate breakdown during measurement. This was done based on prior industrial research carried out at the factories. $30 \mathrm{~g}$ of powder was weighed out and mixed with $1 \%$ (wt/wt) Syloid 244 FP flow agent from Grace Davison, as IWMP has poor flowability characteristics. The powder was then fractionated using 125 and $355 \mu \mathrm{m}$ aperture sieves, $200 \mathrm{~mm}$ in diameter, with a vibratory Retsch AS200 sieve shaker for 30 minutes at an amplitude of $1.8 \mathrm{~mm}$. The powder remaining on each sieve was weighed and the sieves were then cleaned with detergent and dried before the next analysis.

\subsection{Plant Data Collection}

The change in bulk density has historically been used to evaluate the powder breakdown during in-plant transport, as bulk density is a simple routine measurement. It is regularly measured 
at the packer and also at the end of the fluidised beds. The procedure is similar to the ISO 8967|IDF 134:2005 standard, which involves weighing a fixed volume of powder after a exposure to a pre-determined number of taps using a mechanical tapping machine.

Because the bulk density depends on the particle size distribution, it was expected that it could be used as a proxy in order to be able to analyse a larger dataset. This data is not collected at Plant A as it consistently produces superior quality powder. However, these data were gathered and matched with the instant quality data over the last four years of production for Plant B. Plant B was also more suitable for evaluating the effect of breakdown within a plant as it does not consistently produce superior quality product, and therefore whether large powder breakdown during transport caused poorer quality powder could be analysed.

\section{Results and Discussion}

\subsection{Final PSD Comparison between the Different Plants}

A number of milk powder samples were analysed at the packer to characterise the particle size distribution using both sieving and laser diffraction. The results are shown in Figure 4 and it is clear that Plant $\mathrm{A}$, with the bucket elevator, produces powder with a larger average particle size. The summary statistics from the sieving and laser diffraction data are shown in Table 1, with Plant A having almost $10 \%$ fewer fine particles $(<125 \mu \mathrm{m})$ and $10-15 \%$ more coarse particles $(>355 \mu \mathrm{m})$. The fines content of Plant A is consistently well below the maximum fines recommendation for good instant properties outlined in Section 1 from [10], whilst for Plant B it is right on the limit and occasionally breaches it. This is in line with Plant A having superior instant functionality.

Table 1: Comparison of PSD characteristics measured using the laser diffraction instrument and sieving for the two plants at the packer.

\begin{tabular}{l|l|l|l|l} 
Attribute & \multicolumn{2}{|c|}{ Laser Diffraction } & \multicolumn{2}{c}{ Sieving } \\
\hline & $\begin{array}{l}\text { Plant A } \\
\mathbf{n = 8}\end{array}$ & $\begin{array}{l}\text { Plant B } \\
\mathbf{n = 1 8}\end{array}$ & $\begin{array}{l}\text { Plant A } \\
\mathbf{n = 8}\end{array}$ & $\begin{array}{l}\text { Plant B } \\
\mathbf{n = 1 8}\end{array}$ \\
\hline $\mathrm{wt} / \mathrm{vol} \%<125 \mu \mathrm{m}$ & $7.5 \pm 1.9$ & $16.6 \pm 2.6$ & $10.9 \pm 1.8$ & $19.3 \pm 2.3$ \\
\hline $\mathrm{wt} / \mathrm{vol} \%>355 \mu \mathrm{m}$ & $40.9 \pm 8.7$ & $24.7 \pm 4.4$ & $28.1 \pm 8.6$ & $18.4 \pm 3.4$ \\
\hline$d(0.5) \mu \mathrm{m}$ & $312 \pm 37$ & $236 \pm 18$ & N/A & N/A \\
\hline Span $\left[\frac{d(0.9)-d(0.1)}{d(0.5)}\right]$ & $1.48 \pm 0.03$ & $1.67 \pm 0.04$ & N/A & N/A \\
\hline
\end{tabular}




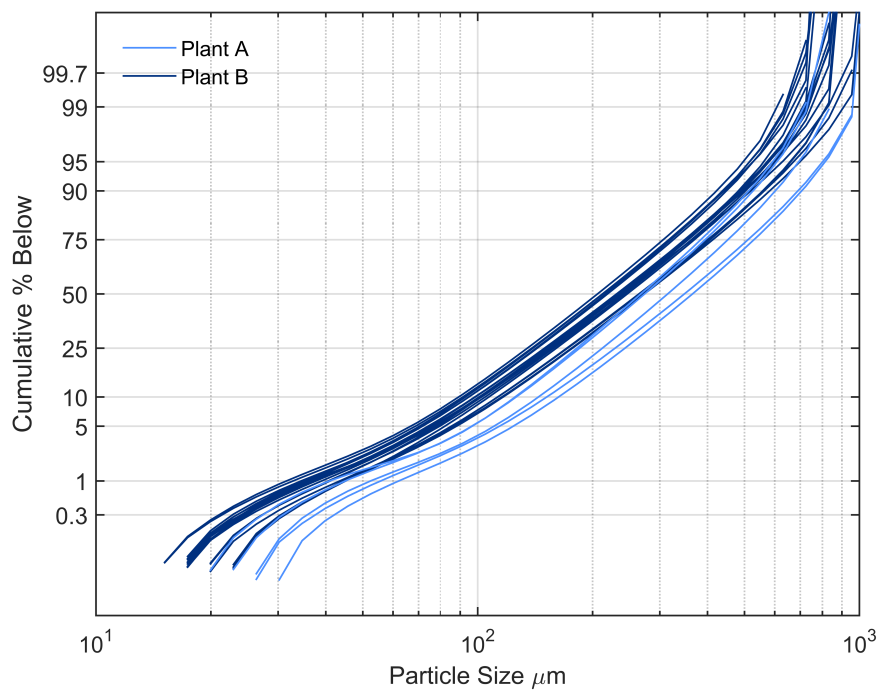

Figure 4: Comparison of laser diffraction cumulative particle size distributions from powder produced at the two plants for a number of samples taken from the packer.

\subsection{Plant Breakdown Comparison using Laser Diffraction}

Examples of cumulative distribution graphs showing the breakdown at Plants A and B are shown in Figure 5. A shift in the distribution to a smaller average particle size can be seen. A clear decrease in the particle size can be seen at Plant A, where little breakdown was expected due to the bucket elevator system that is in use.

The median particle size change was used to compare the breakdown from the different samples. The results of these are shown in Figures $6 \mathrm{a}$ and $6 \mathrm{~b}$. Given the change in the median particle size, Plant A showed at least as large a decrease in particle size compared with Plant B, if not larger. The graph also shows, with $95 \%$ confidence intervals, that the larger the initial particle size, the larger the breakdown, irrespective of the plant conveying method. However, even though the powder with the larger initial particle size experiences more breakdown, the net effect is that it still has a larger particle size at the packer, as shown in Figure 6b. Plant A always has a significantly lower fraction of fine particles, in spite of having at least as high a breakdown during transport. This means that an initially larger particle size is more important than the absolute change during transport, as it can compensate for agglomerate breakdown.

This data suggests that if the the particle size is sufficiently large initially, then particle breakdown is less relevant to the final dissolution properties of the powder, as Plant A exhibits superior instant properties to Plant B. If the initial powder has a larger fines content at the 


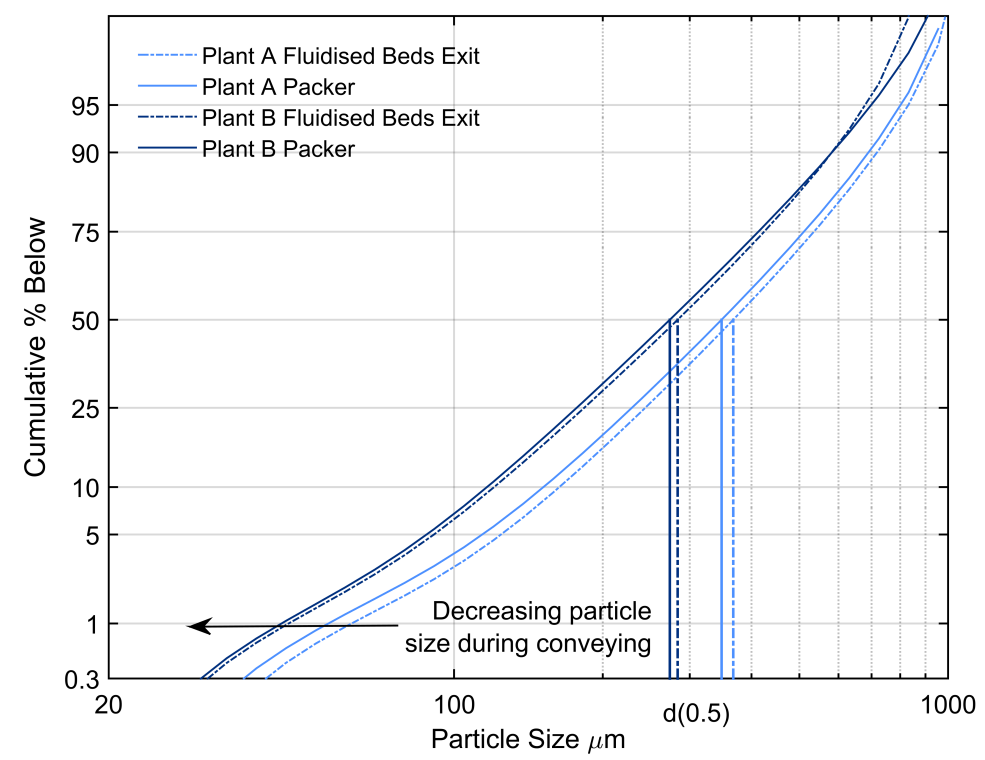

Figure 5: Example showing the variation in PSD from the fluidised beds to the packer for the two different plants.

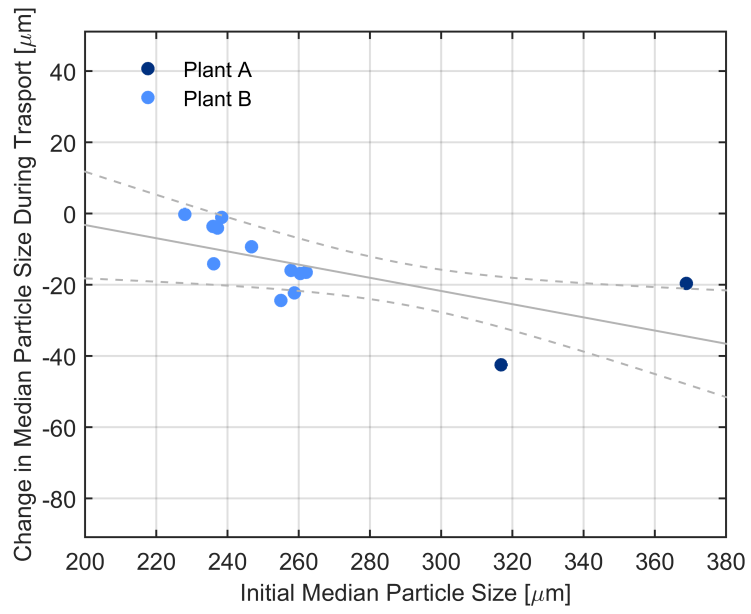

(a)

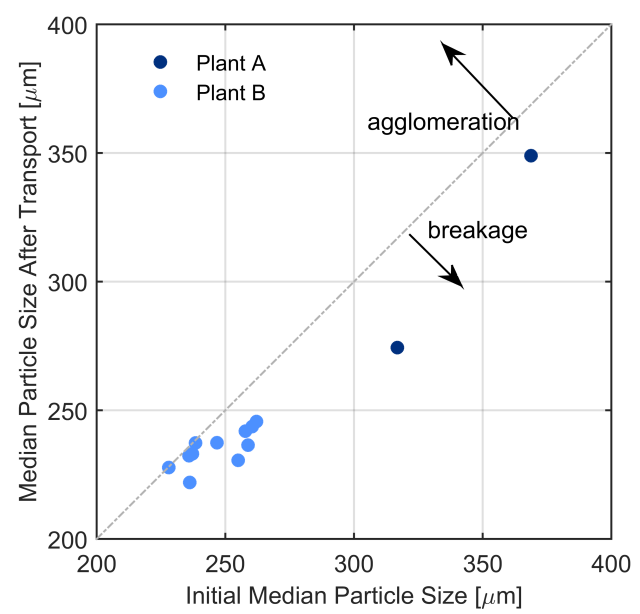

(b)

Figure 6: Evaluation of breakdown of powder a) effect of initial median particle size on the absolute change in the median size post transport and b) final versus initial median particle size measured using laser diffraction. 
outset, the fines would increase even further during transport, and would be expected to worsen the instant functional properties. However, it was suspected that due to the "aggressive" dry air dispersion system (in the measuring instrument) that some of the milk powder was broken down during the analysis, and hence biasing the particle size measurements. This was expected to affect the pre-transport powder the most as the most fragile particles would not yet have been broken down by conveying. Sieving was therefore used to test this, by comparing sieving with laser diffraction results and verifying the comparison of the breakdown between the two plants.

\subsection{Verification of Plant Breakdown Using Sieving}

An equally large particle breakdown at the two plants was unexpected. A comparison of the percentage of coarse particles measured using sieving and laser diffraction by sample location is shown in Figure 7. Samples were compared from a number of locations, including two extra ones: the exit of the cyclones and from the entrance to the powder storage bins. Figure 7 shows that as the sample progresses through the conveying system, from the fluidised beds to the bin entrance, and then finally the packer, the more coarse particles were measured by laser diffraction relative to sieving. This implies that as the particles became less fragile, laser diffraction could measure more of them because they were not destroyed by the air dispersion system in the instrument prior to measurement. The coarse fraction measured at the outlet of the cyclones showed a similar relationship to that of the packer, and these two sampling locations were expected to have only the most robust particles remaining.

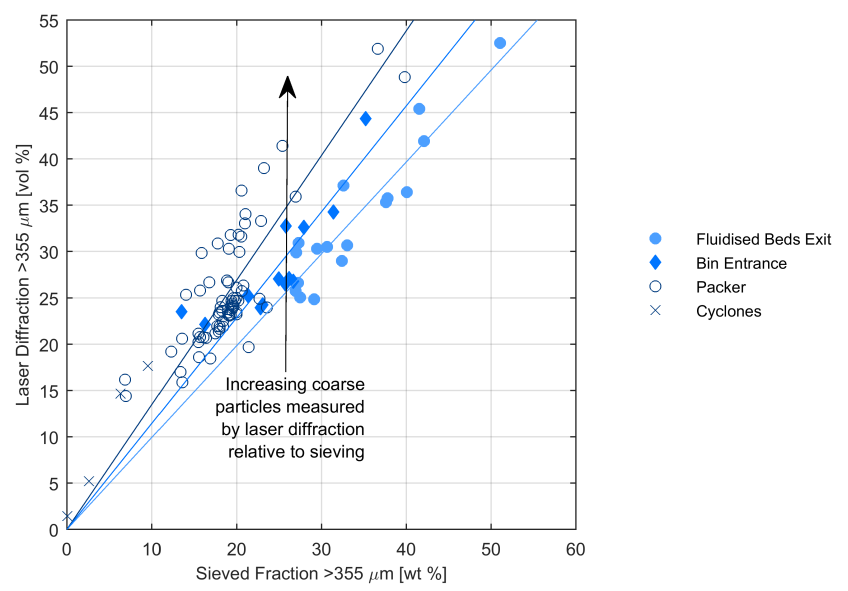

Figure 7: Comparison of the coarse particle fraction $(>355 \mu \mathrm{m})$ measured using laser diffraction and sieving from different sample locations. 
Sieving was then used to verify that the original results were not due to attrition of the fragile powder in the laser diffraction instrument during measurement. The change in fines content measured using sieves and the laser diffraction instrument are shown in Figures 8a and $8 \mathrm{~b}$ respectively. As anticipated, the overall increase in fines due to in-plant conveying is smaller when measured using laser diffraction, indicating that the dry powder dispersion system of the instrument is breaking the powder down before measurement. However, the overall trend is the same; sieving also shows that the increase in fine particles for Plant A is of the same magnitude as Plant B.

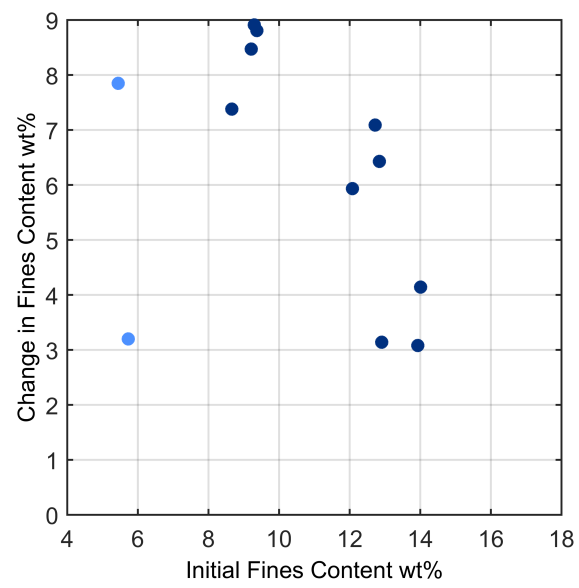

(a)

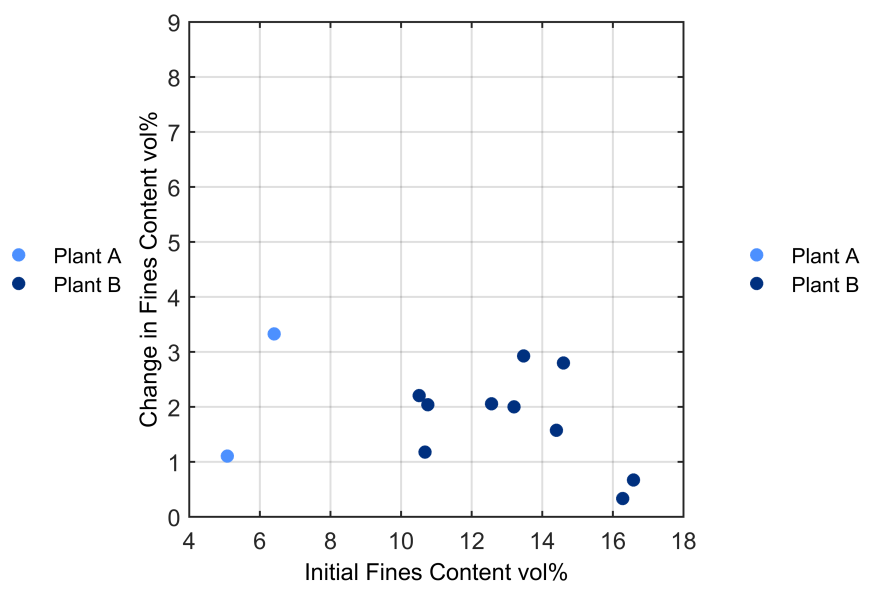

(b)

Figure 8: Change in fines content, particles $<125 \mu \mathrm{m}$ from end of the fluidised beds to the packer measured using a) sieving b) laser diffraction instrument.

Similar to the conclusions from the laser diffraction instrument measurements, the sieving results presented in Figure 9a show that generally the larger the fines content pre-transport, the larger the fines content post transport. In other words, the final packer particle size is most significantly impacted by the initial particle size. Thus, the focus for achieving the right particle size at the packer should be on achieving the right particle size at the dryer at the outset. It can then compensate for transport through the system, which cannot be avoided, nor changed significantly once installed. Therefore, the difference in functionality of the powders produced by the two plants is unlikely to be contributed to by the significantly different powder conveying systems. 


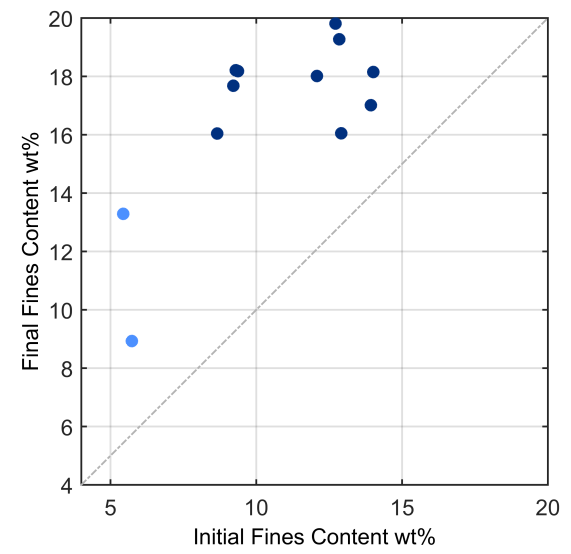

(a)

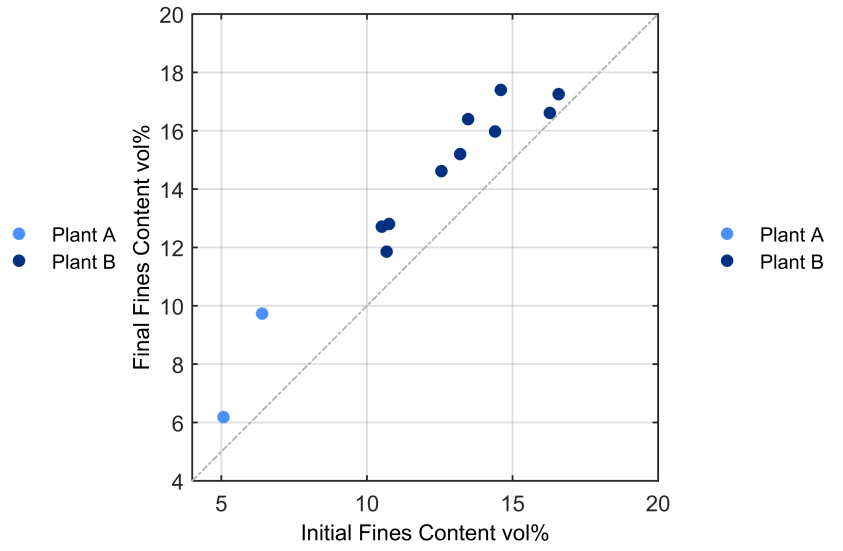

(b)

Figure 9: Effect of initial fines content on final fines content, particles $<125 \mu \mathrm{m}$, as measured using a) sieving b) laser diffraction instrument.

\subsection{Effect of Breakdown Within a Single Plant}

Although the difference in functionality between the two plants is not primarily due to differences in the plant transport systems, this does not answer the question of whether optimising transport to minimise breakdown would benefit the final functional properties at an industrial plant. Data for the change in the particle size was not available, as particle size is not a routine production measurement. However, breakdown can also be measured using the bulk density change, which is a routine measurement, and bulk density measurements at the end of the fluidised beds and packer were available for multiple seasons of production at Plant B.

The change in bulk density was used as an alternative measure of the breakdown experienced by the powder in the transport chain. At the industrial plants it was assumed that a larger change in bulk density corresponded to a larger particle breakdown. The historical data was gathered for multiple years of production and matched with the dispersibility and wettability functional testing results in order to evaluate if powder with better functionality had experienced on average less breakdown during transport.

Figure 10 shows the box plots of the breakdown seen by the milk powder having good and poor dispersibility and wettability from the same plant. The superior dispersibility and wettability powder does not show a clear trend of overall lower change in bulk density from the end of the fluidised beds to the packer.

A two sample t-test from independent measurements was performed to statistically compare the means. The plant data characteristics are summarised in Table 2. The change in bulk density 


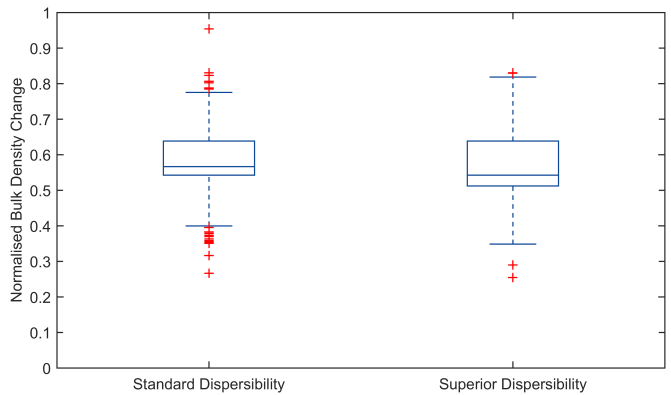

(a)

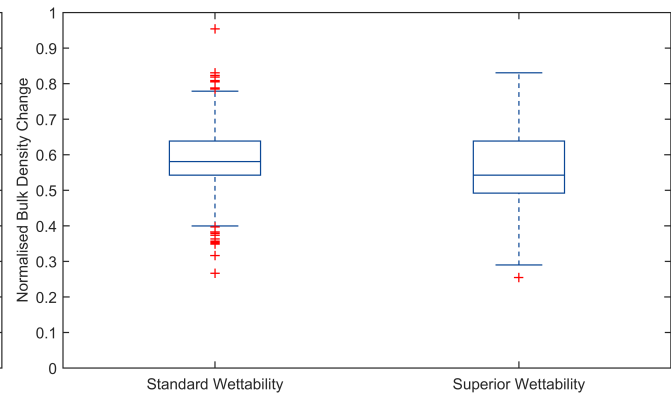

(b)

Figure 10: Box plots showing the bulk density breakdown during powder transport for standard and superior functionality powders a) dispersibility b) wettability.

has been normalised (for confidentiality reasons), with 0 and 1 representing the minimum and maximum bulk density change experienced during the production days analysed. No statistically significant difference was found between the mean of samples having standard and superior dispersibility at the $95 \%$ confidence level with a $p$-value of 0.50 . However, a statistically significant difference was found for wettability with a $p$-value of 0.0065 . Therefore, it appears that powders with superior wettability had on average experienced lower breakdown, whereas there appears to be no link between superior dispersibility and the degree of breakdown experienced by the powder.

Table 2: Sample characteristics of powder produced from Plant B used to compare effect of breakdown on functionality.

\begin{tabular}{l|l|l|l|l|l}
$\begin{array}{l}\text { Functional } \\
\text { Property }\end{array}$ & Classification & $\begin{array}{l}\text { Normalised } \\
\text { Mean } \\
\text { Breakdown }\end{array}$ & $\begin{array}{l}\text { Standard } \\
\text { Deviation }\end{array}$ & $\begin{array}{l}\text { Sample } \\
\text { Size }\end{array}$ & $\begin{array}{l}\text { Two sample t- } \\
\text { test } \boldsymbol{p} \text {-value }\end{array}$ \\
\hline Dispersibility & Standard & 0.580 & 0.101 & 401 & 0.5 \\
& Superior & 0.575 & 0.108 & 294 & \\
\hline Wettability & Standard & 0.584 & 0.103 & 508 & 0.0065 \\
& Superior & 0.560 & 0.106 & 187 & \\
\hline
\end{tabular}

However, in Sections 3.2 and 3.3 it was found that the degree of the breakdown depends on the initial particle size, i.e. that the larger the initial size, the larger the degree of breakdown experienced. This can also be seen in Figure 11 where the lower the normalised bulk density change, the higher the bulk density pre-conveying at the fluidised beds. Figure 11 also shows that if the bulk density is sufficiently low pre-conveying, then the wettability remains fast, as represented by the circled region on the graph. Therefore the breakdown cannot be considered independently of the state of the powder pre-conveying. 


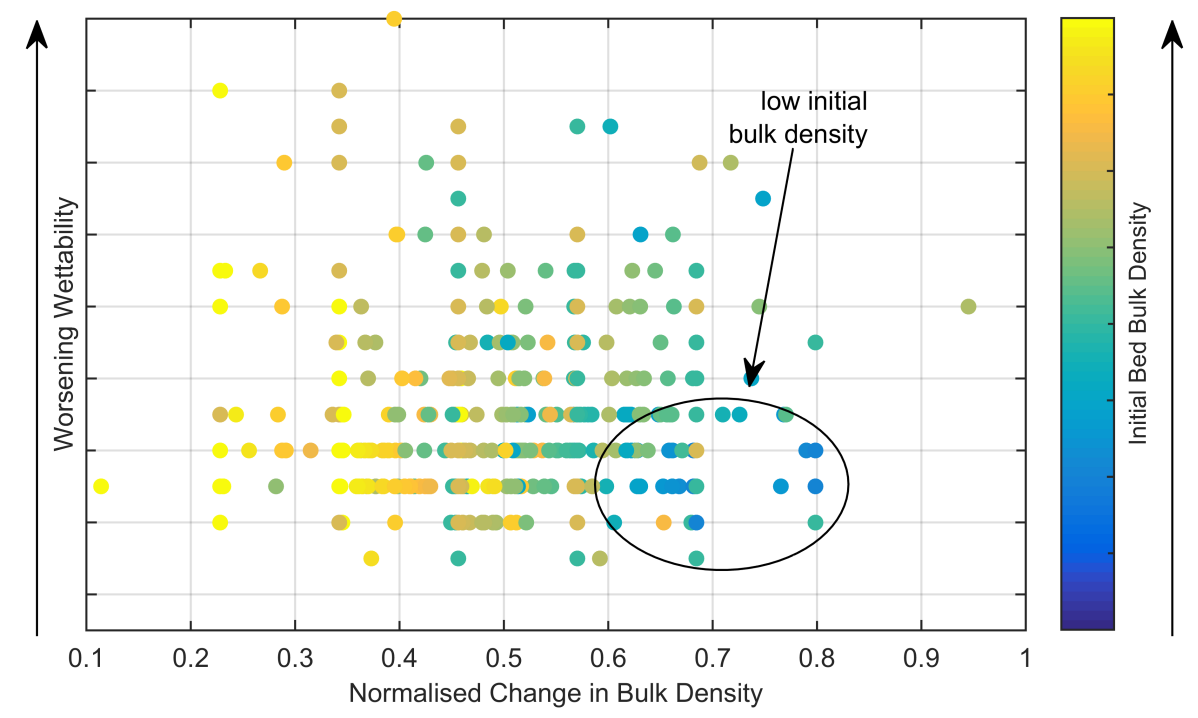

Figure 11: Scatter plot showing the effect of breakdown and initial bulk density before transport on wettability.

\section{Conclusions}

The breakdown of IWMP during processing was studied at two different industrial plants. The particle size distribution affects the instant dissolution properties of the powder, with excess fine particles being detrimental to the powder functionality as hypothesised by [10]. It was expected prior to this study that the plant with the more "gentle" powder transport system (i.e. conveyor) had a larger final particle size due to less powder breakdown. However, the breakdown was found to be similar in both plants irrespective of the conveyor type. The powder from the plant (A) with the larger final particle size had significantly larger particles prior to transport, which provided a larger buffer for breakdown and thereby better dissolution properties. This indicates that to achieve the ideal IWMP particle size, the focus should be on achieving a larger particle size initially.

Similarly, when analysing breakdown using bulk density data at one of the plants, it was found that powder with superior dispersibility did not experience a larger average bulk density change. Although powder with superior wettability did have a larger average bulk density change, on further examination it was found that the initial bulk density of the powder was equally important. If the initial bulk density was sufficiently low, then this could compensate for the breakdown and the wettability time remained low (i.e. good). Therefore the initial powder state pre-conveying was important.

Overall, the results indicate that optimising conveying system is not the only way to compen- 
sate for breakdown, and the focus should equally be on producing powder of the right agglomerate size and bulk density prior to transport in order to compensate for the inevitable powder attrition.

\section{Acknowledgements}

The authors would like to acknowledge the Primary Growth Partnership program from the New Zealand Ministry of Primary Industries for funding the project and would also like to thank Fonterra and specifically James Winchester, Richard Croy, Hong Chen, Steve Holroyd and Nigel Russell for providing resources and support throughout the project.

\section{Bibliography}

[1] Nurşin Baş, Pankaj B. Pathare, Muammer Catak, John J. Fitzpatrick, Kevin Cronin, and Edmond P. Byrne. Mathematical modelling of granola breakage during pipe pneumatic conveying. Powder Technology, 206:170 - 176, 2011.

[2] Gustavo V. Barbosa-Cánovas, Enrique Ortega-Rivas, Pablo Juliano, and Hong Yan. Food Powders: Physical Properites, Processing and Functional. Klwer Academic/Plenum Publishers, New York, 2005.

[3] G. B. Basim and M. Khalili. Particle size analysis on wide size distribution powders: Effect of sampling and characterization technique. Advanced Powder Technology, 26(1):200 - 207, 2015 .

[4] Pierre Chapelle, Nicholas Christakis, Hadi Abou-Chakra, Ian Bridle, M.S.A. Bradley, Mayur Patel, and Mark Cross. Computational model for prediction of particle degradation during dilute-phase pneumatic conveying: Modeling of dilute-phase pneumatic conveying. Advanced Powder Technology, 15(1):31 - 49, 2004. ISSN 0921-8831.

[5] Kevin J. Hanley, Edmond P. Byrne, Kevin Cronin, Jorge C. Oliveira, James A O'Mahony, and Mark A. Fenelon. Effect of pneumatic conveying parameters on physical quality characteristics of infant formula. Journal of Food Engineering, 106:236 - 244, 2011.

[6] T. J. Hunter, N.T. Russell, D. I. Wilson, B. R. Young, T. Munir, and N. Depree. Developing 
a real-time quality programme for dairy. In Chemeca, 23-36 September 2012, Wellington, New Zealand, 2012.

[7] H. Kalman. Attrition of powders and granules at various bends during pneumatic conveying. Powder Technology, 112:244 - 250, 2000.

[8] M. T. Munir, W. Yu., B. R. Young, and D. I. Wilson. The current status of process analytical technologies in the dairy industry. Trends in Food Science \& Technology, 43(2), 2015.

[9] Dr. I. J. Pisecky. Handbook of Milk Powder Manufacture. GEA Process Engineering A/S, Copenhagen, 2012.

[10] Ing. Jan Pisecky. Handbook of Milk Powder Manufacture. Niro A/S, Copenhagen, 1997.

[11] P. Schuck. Dehydrated Dairy Products - Milk Powder: Physical and Functional Properties of Milk Powders in Encyclopedia of Dairy Sciences. Academic Press, San Diego, second edition edition, 2011.

[12] T. Taylor. Specific energy consumption and particle attrition in pneumatic conveying. Powder Technology, 95(1):1 - 6, 1998. ISSN 0032-5910. 